\section{AL-AZHAR}

Assiut Dental Journal
The Official Publication of The

Faculty of Dental medicine.

Al-Azhar Assiut Uniuersity.

AADJ, Vol. 3, No. 2, October (2020) - PP. 121:128

ISSn 2682-2822

\title{
Clinical and Radiographic Evaluation of Fresh Socket Grafting using Beta-tri-calcium Phosphate with Collagen and Platelet-Rich Fibrin for Receiving Dental Implant
}

\author{
Mahmoud Ali Elsaid ${ }^{* 1}$, Akram Abbas El-Awady ${ }^{2}$, Mohamed Fouad Edrees" ${ }^{* 1}$, Mostafa Mohamed Hosny ${ }^{2}$
}

Codex : 15/2020/10

Aadj@azhar.edu.eg

\section{KEYWORDS}

Keywords: Socket preservation, Defective socket, Beta-tri-calcium phosphate, Platelet rich fibrin , Cone beam computed tomography

1. Department of Oral Medicine, Periodontology, Oral Diagnosis and Dental Radiology, Faculty of Dental Medicine, (Assuit, boys), Al-Azhar University, Egypt.

2. Department of Oral Medicine, Periodontology, Oral Diagnosis and Dental Radiology, Faculty of Dental Medicine, (Cairo, boys), Al-Azhar University, Egypt.

* Corresponding Author e-mail: mohamededrees.dent.ast.b@ azhar.edu.eg

\begin{abstract}
Aim: To compare the clinical and 3D volumetric socket bone preservation using Beta tri- calcium pohosphate plus collagen (B-TCP/Col) versus Platelet Rich Fibrin (PRF) assessed by 3D cone beam computed tomography. Subjects and Methods: 20 patients were treatment planned for extraction of mandibular and maxillary teeth, leaving 20 sockets for the study. Sockets were divided into 2 groups, each group consisting of 10 sockets. Sockets were grafted as follows: Group (I) sockets were grafted with B-TCP/col, Group (II) sockets were grafted with PRF. Cone beam computed tomography $(\mathrm{CBCT})$ were done immediately and 3 months postoperatively, then collected data were statistically analyzed. Results: After 3 months, Bone height (mm) showed significant difference between the tested groups where Group A (B-TCP) produced the highest mean Bone height followed by Group B (PRF) . Bone width (mm) showed insignificant differences between the tested groups. Bone density showed insignificant differences between the tested groups. Conclusion: Beta tri calcium pohosphate plus collagen (B-TCP/Col) may be a adjunctive modality to accelerate bone formation in defective socket.
\end{abstract}

\section{INTRODUCTION}

Maintenance of the natural dentition in optimal conditions of health, function and aesthetics, with the ultimate goal of enhancing the wellbeing of patients, remains as the main objective of periodontal therapy. In clinical scenarios involving a hopeless tooth indicated for extraction, and considering future replacement with an implant, adequate management of the extraction site may contribute to achieve predictable and satisfactory outcomes. ${ }^{(1)}$

Tooth extraction triggers a cascade of biological events, mediated by both the local inflammatory response that follows the surgical intervention and the deprivation of masticatory stimulation of the periodontium, which elicit an alteration of the homoeostasis and structural integrity of the periodontal tissues. As a consequence, a physiologic process of 
disuse atrophy, characterized by an intense resorption of the alveolar bone and a partial invagination of the mucosa, takes place over the first weeks after tooth extraction. ${ }^{(2-5)}$

In an attempt to attenuate the resorptive events that follow tooth loss and to minimize the need for ancillary ridge augmentation procedures prior to delivery of implant-and/ or tooth-supported restorations, different interceptive therapies have been proposed, including partial extraction protocols, forced orthodontic extrusion and alveolar ridge preservation (ARP) performed immediately after complete tooth extraction. ${ }^{(6)}$

A wide variety of ARP treatment modalities have been described in the past 20 years, including socket preservation with bone grafting, including autografts, allografts, xenografts, and alloplasts alone or in combination with absorbable or nonabsorbable membrane. (7)

\section{PATIENTS, SUBJECTS AND METHODS}

This study was designed as a randomized controlled clinical and radiographic study carried out on a total twenty patients of both sexes ( 10 females and 10 males ranged in age from 19-40 years). All patients were selected from those planned for extraction of one or more hopless tooth followed by delayed implant placement

\section{Clinical Parametrs}

To standardize the measurement of clinical parameters, acrylic stents for the extraction site were fabricated on the cast models of the dentition prepared during the treatment planning appointment using self-cure clear acrylic resin.

Mid-buccal crestal height: Measured as the distance in millimeters from a fixed reference point (FRP) on the acrylic stent to the most coronal midbuccal crestal point on the buccal cortical plate using graduated periodontal prob.

Mid-palatal/lingual crestal height: Measured as the distance in millimeters from a fixed reference point (FRP) on the acrylic stent to the most coronal mid-palatal/lingual crestal point on the palatal/lingual cortical plate using graduated periodontal prob.

Relative socket depth: Measured as the distance in millimeters from the central hole on the acrylic stent to the most apical end of the socket/ ridge using (no.20) spreader with a stopper.

Bucco-lingual width: Buccolingual width was measured corresponding with the line (line 1), $2 \mathrm{~mm}$ apical to coronal most point on the socket/residual ridge using Ridge Mapping Caliper (GDC, Punjab, India). Local infiltration was used while measuring buccolingual dimension at 3 months follow-up.

\section{Radiographic Parameters:}

- Radiographic (CBCT) parameters were recorded within $24 \mathrm{~h}$ after the surgery and after 3 months.

- Analysis of dental CBCT scan images was done using New Tom cone beam 3D system. Fig(1)

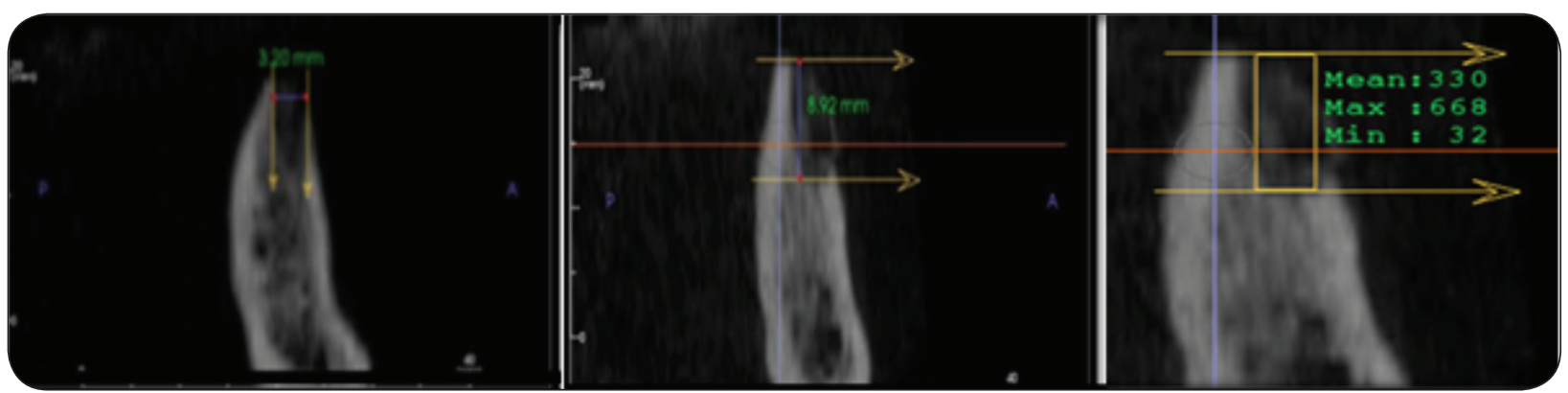

Fig. (1) 
Bone Height measurments: At the generated cross-sectional view, two tangential lines were drawn passing through the highest and lowest point of the socket, and then the distance between these two lines was measured in millimeters.

Bone width measurments: At the generated cross-sectional view, two tangential lines were drawn passing through the most buccal and most lingual/palatal points of the socket and then the distance between these two lines was measured in millimeters.

Bone density measurements: At the generated cross-sectional view, three density readings were taken for each site (Crestal, middle and apical) then the mean of the three readings was acquired.

\section{Statistical analysis}

Recorded data were analyzed using the statistical package for social sciences, version 20.0 (SPSS Inc., Chicago, Illinois, USA).

\section{RESULTS}

\section{Clinical parametrs}

- The changes in mid buccal crestal hieght, Midpalatal/lingunl crestsal height, Relative socket depth and buccolingual width were recorded at base line and after 3 months for the two groups. The range between minimum and maximum values, means $\pm \mathrm{SD}, \mathrm{P}$-values and $\mathrm{t}$-values of Group I ( $\beta$ TCP) between baseline and after 3 months illustrated in Table(1)

- Minimum and maximum values, means \pm SD, Pvalues and t-values of Group II (PRF) between baseline and after 3 months illustrated in

- Using: Paired Sample t-test; statistically significant difference between baseline and after 3 months according to Mid buccal cieslal height (mm), Mid-palatal/lingunl crests height ( $\mathrm{mm})$, Relative socket depth ( $\mathrm{mm}$ ) and Buccolingaal Width (mm) of Group I ( $\beta$ TCP).

- Statistically significant difference between baseline baseline and after 3 months according to Mid buccal cieslal height ( $\mathrm{mm})$, Mid-palatallingunl crests height (mm), Relative socket depth $(\mathrm{mm})$ and Burcolingaal Width $(\mathrm{mm})$ of Group II (PRF).

\section{Radiographic Paramers}

The changes in Bone height ( $\mathrm{mm})$, Bone Width $(\mathrm{mm})$, Bone Density and were recorded at base line and after 3 months for the two groups. The range

Table (1): Showing mean difference, change, t-values and P-values of Mid-buccal crestal height, Midpalatal/lingunl crestal height, Relative socket depth and Buccolingual width in mm in Group I ( $\beta T C P / C o l)$ and Group II between baseline and after 3 months

\begin{tabular}{|l|c|c|c|c|c|c|}
\hline \multicolumn{2}{|l|}{} & \multicolumn{2}{|c|}{ Paired t. test } & \multicolumn{2}{c|}{$\begin{array}{c}\text { Independent } \\
\text { t. test }\end{array}$} \\
\hline Group I $(\beta T C P / C o l)$ & Baseline & After 3months & t-test & p-value & $\begin{array}{c}\text { Base line } \\
\text { p-value }\end{array}$ & $\begin{array}{c}3 \text { months } \\
\text { p-value }\end{array}$ \\
\hline Mid-buccal crestal height & $9.67 \pm 2.87$ & $8.44 \pm 2.80$ & 4.424 & $<\mathbf{0 . 0 0 1 * *}$ & 0.236 & 0.803 \\
\hline Mid-palatal/lingunl crestal height & $9.12 \pm 2.78$ & $7.45 \pm 2.56$ & 5.400 & $<\mathbf{0 . 0 0 1} * *$ & 0.346 & 0.615 \\
\hline Relative socket depth & $21.35 \pm 3.22$ & $9.79 \pm 3.17$ & 8.968 & $<\mathbf{0 . 0 0 1 * *}$ & 0.786 & $\mathbf{0 . 0 4 4}$ \\
\hline Buccolingal width & $8.84 \pm 3.29$ & $5.58 \pm 1.23$ & 7.944 & $<\mathbf{0 . 0 0 1 * *}$ & $\mathbf{0 . 0 3 7 *}$ & $\mathbf{0 . 0 1 4}$ \\
\hline Group II (PRF) & $7.68 \pm 1.96$ & $8.84 \pm 2.04$ & 4.766 & $<\mathbf{0 . 0 0 1 * *}$ & & \\
\hline Mid-buccal crestal height & $7.49 \pm 2.35$ & $6.61 \pm 2.52$ & 3.152 & $\mathbf{0 . 0 1 2 *}$ & & \\
\hline Mid-palatal/lingunl crestal height & $21.91 \pm 3.08$ & $14.14 \pm 3.09$ & 6.294 & $<\mathbf{0 . 0 0 1 * *}$ & & \\
\hline Relative socket depth & $7.41 \pm 0.88$ & $3.45 \pm 0.88$ & 9.682 & $<\mathbf{0 . 0 0 1 * *}$ & & \\
\hline Buccolingual width &
\end{tabular}


Table (2): Showing t-values and P-values of Bone height, Bone width and Bone denisty in Group I ( $\beta T C P /$ Col)and Group II(PRF) at baseline and after 3 months.

\begin{tabular}{|c|c|c|c|c|c|c|}
\hline \multirow[b]{2}{*}{ Group I ( $\beta$ TCP/Col) } & \multirow[b]{2}{*}{ Baseline } & \multirow[b]{2}{*}{$\begin{array}{c}\text { After } \\
\text { 3months }\end{array}$} & \multicolumn{2}{|c|}{ Paired t. test } & \multicolumn{2}{|c|}{$\begin{array}{c}\text { Independent } \\
\text { t. test }\end{array}$} \\
\hline & & & t-test & p-value & $\begin{array}{l}\text { Base line } \\
\text { p-value }\end{array}$ & $\begin{array}{l}3 \text { months } \\
\text { p-value }\end{array}$ \\
\hline Bone Height & 10.53 & 8.50 & 6.054 & $<0.001 * *$ & $0.004 *$ & $0.041 *$ \\
\hline Bone Width & 6.84 & 5.79 & 2.161 & $0.049 *$ & $0.029^{*}$ & 0.114 \\
\hline Bone Denisty & 512.50 & 603.90 & 1.047 & 0.309 & $0.018^{*}$ & 0.241 \\
\hline \multicolumn{7}{|l|}{ Group II (PRF) } \\
\hline Bone Height & 6.63 & 6.18 & 2.111 & $0.047 *$ & & \\
\hline Bone Width & 4.78 & 4.38 & 0.395 & 0.698 & & \\
\hline Bone Denisty & 295.80 & 593.40 & 4.628 & $<0.001 * *$ & & \\
\hline
\end{tabular}

between minimum and maximum values ,means $\pm \mathrm{SD}$, P-values and t-values of Group I ( $\beta$ TCP) between baseline and after 3 months illustrated in Table(1)

Minimum and maximum values, means $\pm \mathrm{SD}$, P-values and t-values of Group II (PRF) between baseline and after 3 months illustrated in

Using: Paired Sample t-test; statistically significant difference between baseline and after 3 months according to Bone height ( $\mathrm{mm}$ ), Bone Width ( $\mathrm{mm}$ ), Bone Density (mm) of Group I ( $\beta$ TCP).

\section{DISCUSSION}

Post extraction resorption of the alveolar ridge is a progressive and irreversible process following removal of teeth. Bone loss occurs in both the alveolar height and width and is accelerated in the first six months after extraction, and has the potential to either complicate implant placement or impair the final esthetic result. Techniques to preserve natural bone and soft tissue contours are of great interest to clinicians and patients because even subtle postextraction buccal plate resorption may have significant clinical effects, particularly in the esthetic zone.
Loss of ridge height and width results in prosthetic instability and complicated esthetic tooth replacement with implants which may require extensive reconstructive surgery later on. ${ }^{(8)}$

Alveolar ridge preservation is a procedure undertaken following an extraction, which is designed to minimize alveolar ridge resorption and maximize bone formation within the socket. However, there are clinical situations where it is not advisable to use ridge preservation at the time of extraction as in cases of acute infection. In these situations, preservation of the ridge may be delayed by six to eight weeks post-extraction. ${ }^{(9-10)}$

The rational behind ridge preservation is modulation of early stage ridge resorption, increasing bone density and facilitating future implant placement. ${ }^{(11)}$

Several solutions have been proposed for preserving extraction socket; atraumatic extraction of the tooth, immediate implant placement ${ }^{(12-13)}$ grafting materials with or without barrier membrane, ${ }^{(14-15)}$ and also barrier membrane alone can used without grafting materials. ${ }^{(16)}$

Different grafting materials have been used including; autogenous bone graft harvested from on 
site to another within the same individual, allograft transferred between members of the same species, xenografts from different species as bovine bone graft and alloplasts which are synthetic in origin. ${ }^{(17)}$ The use of autogenous bone has always been the gold standard, but at times, autogenousbone harvesting is not feasible, where now the alternatives are allografts, xenografts or alloplastic materials ${ }^{(18)}$

The present study aimed to compare clinically and radiographically the potentiality of both betatricalicium phosphate covered with collagen membrane and PRF plugs in preservation of the alveolar ridge and reducing the bone dimensional changes following tooth extraction in sites planned for delayed implant placement.

The present study used Platelet-rich fibrin (PRF) plugs as a autologus grafting material for the extraction socket. PRF is the second-generation of platelet concentrate that has been used in various surgical procedures in an attempt to enhance wound healing because the high concentrations of the collected platelets allow for the slow release of growth factors at a sustained rate over a longer period, thereby optimizing wound healing . ${ }^{(19)}$

During present study was recoreded clinically rapid healing process of wound tissue and minimal postoperative pain without any signs of neither infection nor inflammation.

The classical technique for PRF preparation that invented by Dr. Choukroun, in 2000 was followed in the current study due to its simplicity, safty from transmitted diseases and elimination of anticoagulant usage. ${ }^{(20)}$

Clinical outcomes:Vertical bone parameters including Mid-buccal crestal height, Mid-palatal/ lingunl crestal height, buccu-lingual width and Relative socket depth exhibited noticeablemay also facilitate primary wound closure via fibroblast chemotactic properties, which achieves predictable treatment outcomes All the clinical parameters were recorded from an fixed reference points on the acrylic stent fabricated on the cast as advocated by Talwar et al 2010 because this technique provide an accurate method for linear measurments and repreducability during different follow-up intervals. ${ }^{(21)}$

- At baseline, all the clinical parameters except relative socket depth of Group II (PRF) were higher in contrast to that of Group I (BTCP).

- At 3 months, except for mid-buccal crestal height for which an increase in Group I (PRF) was observed.

- For all the other parameters both the groups showed a reduction.

- The reduction was higher in Group II ( $\beta$-TCP$\mathrm{COl}$ ) as compared to Group I (PRF) for all the parameters and difference between two groups was also significant $(P<0.05)$

- In the present study showed more decrease in buccolingual width of Group II (PRF) than Group I ( $\beta$-TCP-Cl) after 3 months and GroupIwere produced the highest bone width followed by Group II.

- Radiographic outcomes :Quantity of bone formation in the form of linear measurement of Bone height exhibited noticeable preservation of the extraction socket and reduction of the degree of alveolar bone loss in both $\beta$ TCP-Col and PRF groups while Bone width showed statistically significant only in $(\beta \mathrm{TCP} / \mathrm{Col})$ group when the ridge dimensions at 3 months compared with those at base line with favourable results to $\beta$ TCP-Col group over PRF group after complete healing of the extraction socket.

- Within Group I ( $\beta$-TCP-Cl), mean density values were highest in the middle third followed by coronal third and least in the apical third, whereas for Group II (PRF) mean density values were highest in the middle third followed by apical third and least in the coronal third at 3 months follow-up. In contrast to results obtained from earlier studies, where more evident density was 
observed in apical part of the socket/ridge as compared to the coronal and middle third.and this is agree with[ Madan R, Mohan R, Bains VK2014) $)^{(22)}$

- Significant reduction on mean bone height (mm) were found after 3 months $(8.5 \pm 2.42 \mathrm{~mm})$ compared to Immediate $(10.53 \pm 2.72 \mathrm{~mm})$ at $\mathrm{p}=<0.001$ for Group A (B-TCP).

- Significant reduction on mean bone height $(\mathrm{mm})$ were found after 3 months $(6.18 \pm 2.29$ $\mathrm{mm})$ compared to Immediate $(6.63 \pm 2.6 \mathrm{~mm})$ at $\mathrm{p}=0.047$ for Group B (PRF).

\section{REFERENCES}

1. AAP. (2011). Comprehensive periodontal therapy: A statement by the American Academy of Periodontology. JournalofPeriodontology,82,943-949.

2. Araujo,M.G.,\&Lindhe,J.(2005).Dimensionalridgealterations following toothextraction. Anexperimentalstudyinthedog. Journal of Clinical Periodontology, 32, 212-218. https://doi. org/10.1111/j.1600-051X.2005.00642.x.

3. Chappuis, V., Engel, O., Reyes, M., Shahim, K., Nolte, L. P., \& Buser, D. (2013). Ridge alterations post-extraction in the esthetic zone: A3D analysis with CBCT. Journal of Dental Research, 92, 195S-201S.

4. Discepoli, N., Vignoletti, F., Laino, L., de Sanctis, M., Munoz,F., \& Sanz, M. (2013). Early healing of the alveolar process after tooth extraction: An experimental study in the beagle dog. Journal of Clinical Periodontology, 40, 638-644. https://doi.org/10.1111/jcpe.12074

5. Trombelli, L., Farina, R., Marzola, A., Bozzi, L., Liljenberg, B., \& Lindhe, J. (2008). Modeling and remodeling of human extraction sockets. Journal of Clinical Periodontology, 35, 630-639. https://doi. org/10.1111/ j.1600-051X.2008.01246.

6. Ehrenfest DMD, DelCorso M, Diss A, Mouhyi J, Charrier JB. Three-dimensional architecture and cell composition of a Choukroun's platelet-rich fibrin clot and membrane. J of Periodontol 2010; 81:546-555.

7. Shantipriya Reddy, Prasad MGS, Sanchita Prasad, Nirjhar Bhowmick, Sravya L, Abis Amir, Krishnanad P : Extraction socket preservation using $\beta$ tricalcium phosphate bone graft plug and platelet rich fibrin membrane 2014; 1(1): 39-43
8. Tassos I. and Moe T. Preserving the socket dimensions with bone grafting in single sites: An esthetic surgical approach when planning delayed implant placement. J Oral Implant2007; 33: 156,

9. Chen S. Wilson T. Hammerle C. Immediate or early placement of implants following tooth extraction: review of biologic basis, clinical procedures and outcomes. Int J Oral Maxillofac implants2004; 19:12-25,.

10. Dohan D. Choukroun J. Diss A. Platelet-rich fibrin (PRF): A second-generation platelet concentrate. Part II: Plateletrelated biologic features. Oral Surg Oral Med Oral Pathol Oral Radiol Endod Mar2006; 101, (3) :e45-50.

11. Barry k. and Barteee J. Extraction site reconstruction for alveolar ridge preservation. Part I: rational and material selection. J Oral Implant2001; 27: 187.

12. Barry k. and Barteee J. Extraction site reconstruction for alveolar ridge preservation. Part II: Membrane - assisted surgical technique. J Oral Implant 2001; 27: 194.

13. Tehemer S. philiphanes and Sharawy M. enhancement of osseointegration of implants placed in extraction sockets of healthy and periodontal diseased teeth by using grafting material, an PTFE membrane. Clin implant Dent Rel Res2003; 5 (3):193.

14. Ramachandran P. and jens s. observation on healing of human tooth in extraction sockets implants with PLGA copolymer root replices. Oral Surg Oral Med Oral Pathol 2004. 97:559.

15. Callan D. and Salkaled S. histological analysis of implant sites after grafting with DBM putty and sheets, part I. Implant Dent2000; 9:36,

16. Lekovic V., Camargo P., klokkevold P. and Weinla ender M.: Preservation of alveolar bone in extraction sockets using bioabsorbable membrance. J periodontal 1998. 69:1044-1049;.

17. Tassos I. and Moe T.: Preserving the socket dimensions with bone grafting in single sites: An esthetic surgical approach when planning delayed implant placement. J Oral Implant2007; 33: 156.

18. Minsk L.: Extraction-site ridge preservation. Compend Contin Educ Dent2005.;26(4):272, 274-6, Apr. bovine bone and beta-tricalcium phosphate in the canine: A 24-month longitudinal histologic study and morphometric analysis. Int J Ora Maxillofac Impla. 2004;19:357-68

19. Talwar N, Singh BP, Chand P, Pal US. Use of diagnostic and surgical stent: A simplified approach for implant placement. J Indian Prosthodont Soc. 2010;10:234-9. 
20. Aimetti, M., Romano, F., Griga, F. B., \& Godio, L. (2009). Clinical and histologic healing of human extraction sockets filled with calcium sulfate. International Journal of Oral and Maxillofacial Implants, 24, 902-909. J164-. Lindhe

21. Barone, A., Toti, P., Menchini-Fabris, G. B., Derchi, G., Marconcini, S., \& Covani, U. (2017). Extra oral digital scanning and imaging superimposition for volume analysis of bone remodeling after tooth extraction with and without 2 types of particulate porcine mineral insertion: A randomized controlled trial. Clinical Implant Dentistry and Related Research, 19, 750-759. https://doi.org/10.1111/ cid. 12495

22. Cardaropoli G, Araújo M, Hayacibara R, Sukekava F, Lindhe J. Healing of extraction sockets and surgically produced - Augmented and non-augmented - Defects in the alveolar ridge. An experimental study in the dog. J Clin Periodontol. 2005;32:435-40. 


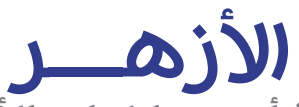 \\ مجلة أسيوط لطب الأسنان
}

النشر الرسمي لكلية طب الأسنان

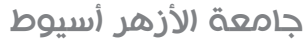

\title{
التقييم الإكلينيكي والإشعاعي لاستخدام بيتا ثلاثي الكالسيوم

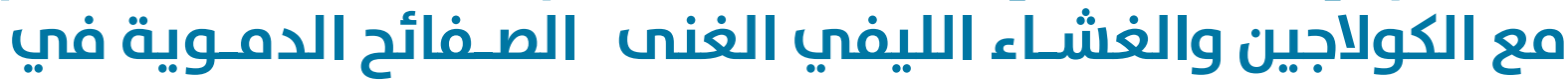

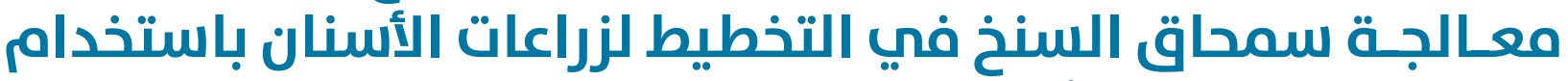 الأشعة المقطعية المخروطية
}

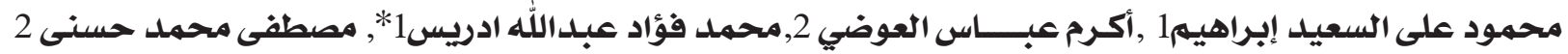

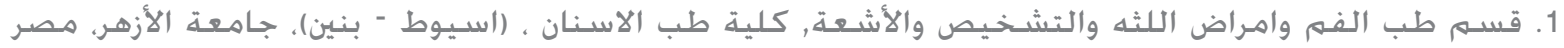

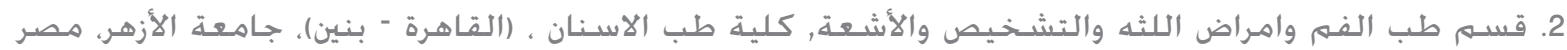

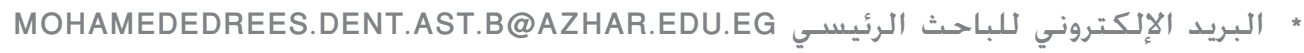

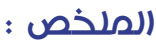

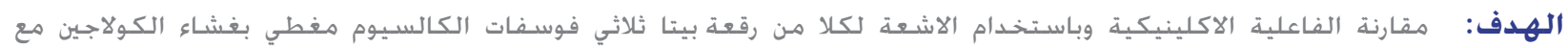

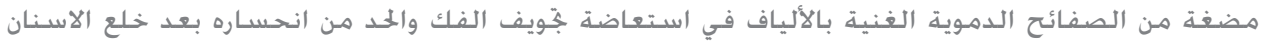

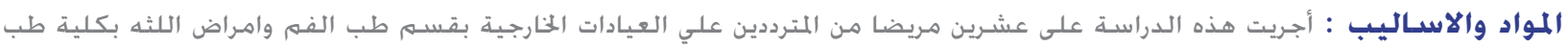

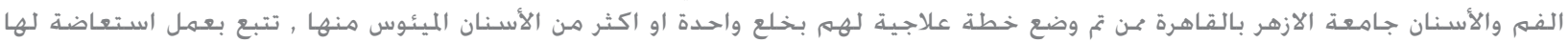

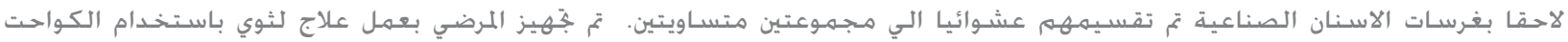

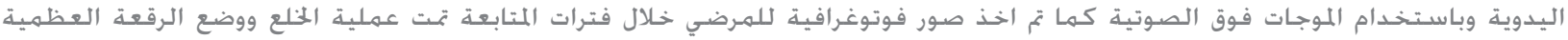

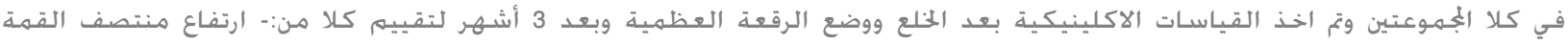

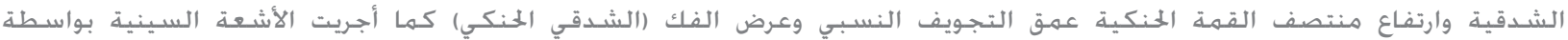

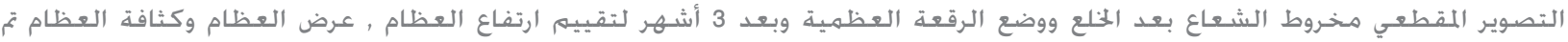
جمع القياسـات وجدولتها وختليلها إحصائيا.

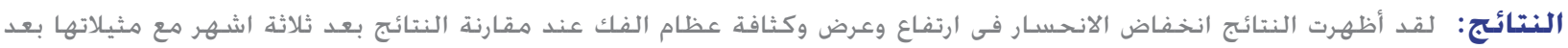

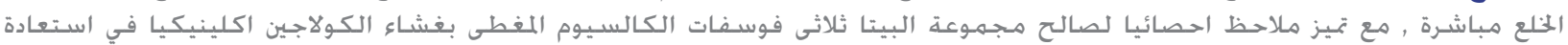

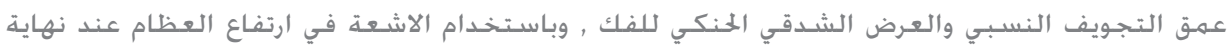

الحنلاصة: من نتائج الدراسـة الحالية نستنتج ان كلا من بيتا ثلاثي فوسـفات الكالسـيوم المغطى بغشـاء الكولاجين والصفائح الدموية الغنية

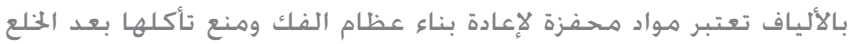

الكعلمات المفتاحية: استعاضه بجّويف الفك, حق ناقص , بيتا ثلاثي فوسفات الكالسيوم ، صفائح غنيه بالألياف ، الحفرة السنخية المعيبة،

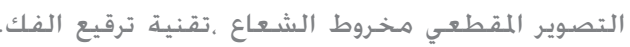

